\title{
Choosing the top people
}

IT Is taking some time to find a successor to Sir Sam Edwards as chairman of the UK Science Research Counoil (SRC), the body that oversees the spending of an annual $£ 100$ million on research projects in universities, institutions and international laboratories. Sir Sam returns to the academic world in October and although feelers have been put about for several months and several people have been approached through the Department of Education and Science, it seems that no one has yet given a favourable reply.

The job is not without its attractions, because even in these days of cash limits it is still possible to pursue modest initiatives rather than simply shore up the status $q u o$; indeed in some ways the power may be greater than before in such matters as postgraduate education, where the universities certainly take more note of SRC's influence and views than in more affluent times. The chairman's job could not really be said to be a post with great appeal to those who have already made their name on the scientific-political scene; strange, then, that one or two of those to whom early feelers went out were people exactly in this category. Maybe commonsense has prevailed-there are several others now being mentioned who have still a name to make; it is surely desirable that with so few scientists privy to the London political scene an imaginative ohoice should be added to their ranks.

The problem confronting many in this category, however, is what to do after a spell at SRC. If a professorship is resigned at the age of 45 , will another professorship or university post conveniently appear at 50 ? If such prospects look bleak, is it possible to keep in touch with the academic world by spending a day or two every week back at the bench and giving SRC three or four days a week? If the chairman finds public service appealing, will opportunities open up for a now-experienced scientist-politician to be employed in ways that are not trivial? Would a chairman with appropriate leanings be able to find a satisfying post in industry?

That these questions have to be posed seriously and are undoubtedly running through the minds of several people interested in this appointment shows how depressingly rigid career structures can be in Britain for senior people of high competence. The last thing that those of ability should have to do is to cling to tenured posts for fear of loss of income or serious erosion of pension; the country surely needs such people to circulate freely and to be able to put their well-experienced minds whole-heartedly to new tasks, probably administrative more than scientific, right into their sixties. There is a serious danger that by consistently failing to encourage free flow between industry, government and the academic world, Britain is wasting much of its senior intellectual resources; the appointment at SRC is just one instance of the sort of dilemma that faces those who genuinely wish to be mobile.

If a top British post in science policy is discussed discreetly by a charmed circle and names are mentioned only on promises of infinite discretion, to preserve the sensibilities of candidates, no such inhibitions seem to surround the procedure of appointing a Presidential Science Adviser in the United States. For weeks before the appoinument is made names are quite openly mentioned as the pros and cons of various candidates are widely discussed. The assumption is, presumably, that aspirants to life in the public eye had better get used early on to being talked about, and that it is better to search out any rational opposition to candidates while there is still time.

Which is the better way of doing things? British concern to protect the individual or American wide exposure? Obviously the question cannot be answered in isolation from recognition of a totally different political and even cultural environment. But even so, there do seem ways in which the appointment of a few of Britain's top science-policymakers could be coupled with much more open consultation, so that the announcement does not come as a complete surprise to virtually all scientists and the name is not greeted with expressions of complete ignorance. This is a matter on which the Department of Education and Science should try to force the pace- they would find mild dissatisfaction with the present system of appointments and a general enthusiasm for more open government amongst scientists. 